\title{
GÊNESE E DINÂMICA DAS AGLOMERAÇÕES URBANAS DE FRONTEIRA: URUGUAIANA E PASO DE LOS LIBRES, CORUMBÁ, PUERTO SUÁREZ E PUERTO QUIJARRO, FOZ DO IGUAÇU, CIUDAD DEL ESTE E PUERTO IGUAZÚ
}

\author{
Cláudia Heloiza Conte ${ }^{1}$
}

\begin{abstract}
Resumo: O artigo analisa a dinâmica econômica e social das aglomerações urbanas de fronteira de Uruguaiana e Paso de los Libres, Corumbá, Puerto Suárez e Puerto Quijarro e Foz do Iguaçu, Ciudad del Este e Puerto Iguazú. Buscou-se compreender as singularidades regionais das aglomerações urbanas em relação à gênese e evolução dos seus centros, levantar e caracterizar as atividades econômicas das aglomerações em diferentes momentos. Verificouse que, mesmo com processos distintos de colonização, Brasil e os países fronteiriços contaram com formações socioespaciais constituídas de elementos similares, mas que suas características próprias, ligadas à localização fronteiriça, distinguem as aglomerações do restante dos respectivos territórios nacionais.
\end{abstract}

Palavras-chave: Gênese; Dinâmica; Aglomeração Urbana de Fronteira

\section{GENESIS AND DYNAMICS OF URBAN AGGLOMERATIONS FRONTIER : URUGUAIANA AND PASO DE LOS LIBRES, CORUMBÁ, PUERTO SUÁREZ AND PUERTO QUIJARRO, FOZ DO IGUAÇU, CIUDAD DEL ESTE AND PUERTO IGUAZÚ}

\begin{abstract}
The article analyzes the economic and social dynamics of the urban agglomerations frontiers of Uruguaiana and Paso de los Libres, Corumbá, Puerto Suárez and Puerto Quijarro and Foz do Iguaçu, Ciudad del Este and Puerto Iguazú. We sought to understand the regional singularities of urban agglomerations in relation to the genesis and evolution of their centers, to raise and characterize the economic activities of agglomerations at different times. It was verified that, even with distinct colonization processes, Brazil and the frontier countries had socio-spatial formations constituted of similar elements, but that their own characteristics, linked to the frontier location, distinguish agglomerations from the rest of their respective national territories.
\end{abstract}

Keywords: Genesis; Dynamic; Urban agglomeration Frontier

\section{GÉNESIS Y DINÁMICA DE LAS AGLOMERACIONES URBANAS DE FRONTERA: URUGUAIANA Y PASO DE LOS LIBRES, CORUMBÁ, PUERTO SUÁREZ Y PUERTO QUIJARRO, FOZ DE IGUAZÚ, CIUDAD DEL ESTE Y PUERTO IGUAZÚ}

Resumen: El artículo analiza la dinámica económica y social de las aglomeraciones urbanas de frontera de Uruguaiana y Paso de los Libres, Corumbá, Puerto Suárez y Puerto Quijarro y Foz de Iguazú, Ciudad del Este y Puerto Iguazú. Se buscó comprender las singularidades regionales de las aglomeraciones urbanas en relación a la génesis y evolución de sus centros, levantar y caracterizar las actividades económicas de las aglomeraciones en diferentes momentos. Se verificó que, incluso con procesos distintos de colonización, Brasil y los países fronterizos contaron con formaciones socioespaciales constituidas de elementos similares,

\footnotetext{
${ }^{1}$ Doutora em Geografia pela Universidade Estadual de Londrina (UEL). Email: claudiaheloiza@yahoo.com.br
} 
pero que sus características propias, ligadas a la localización fronteriza, distinguen las aglomeraciones del resto de los respectivos territorios nacionales.

Palabras clave: Génesis; Dinámica; Aglomeraciones Urbanas de Frontera

\section{INTRODUÇÃO}

O presente trabalho tem como elemento principal a discussão sobre a dinâmica social e econômica das aglomerações urbanas de fronteira de Uruguaiana/RS e Paso de los Libres/AR, Corumbá/MS, Puerto Suárez e Puerto Quijarro/BO e Foz do Iguaçu/PR, Ciudad del Este/PY e Puerto Iguazú/AR, apresentadas no mapa 1.

MAPA 1- Localização das aglomerações urbanas de fronteira: Corumbá, Foz do Iguaçu e Uruguaiana - 2015

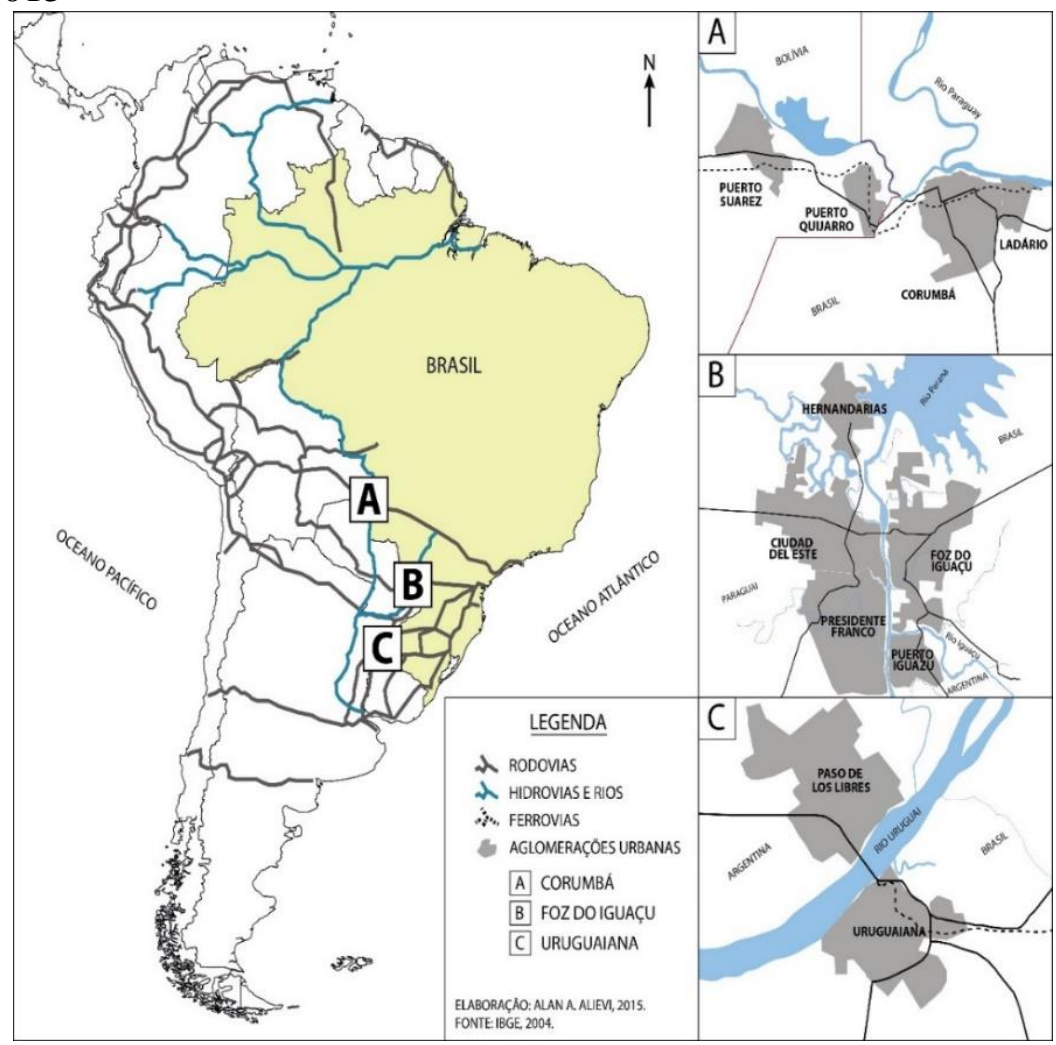

De acordo com o Ministério da Integração Nacional (BRASIL, 2005), tratam-se das aglomerações urbanas de fronteira que possuem maior dinâmica econômica no contexto sul americano. As aglomerações de fronteira em tela tiveram distintos processos de gênese e evolução de seus centros, articuladas a formações socioespaciais diferenciadas. O fato dessas cidades estarem localizadas em áreas de fronteira com outros países sul- americanos, resulta em particularidades em relação às demais cidades dos seus respectivos países.

As conceituações associadas às aglomerações urbanas começaram a ser discutidas com mais profundidade quando grandes centros urbanos passaram por fortes transformações, a partir do crescimento populacional e aumento da produção industrial, bem como do desenvolvimento de sistemas de transportes, que possibilitaram a dispersão da cidade, 
gerando, em muitos casos, aglomerações de centros urbanos de distintos municípios. A conceituação de Beaujeu-Garnier e Chabot (1970, p.21) explicita que, aglomeração urbana é “[...] una noción más extensa que la de ciudad y más precisa que la de área suburbana”, visto tratar-se de uma junção entre duas ou mais cidades, seja pela intensificação de vínculos ou pela expansão territorial urbana.

Parcela importante dos estudos sobre aglomerações urbanas abordam regiões metropolitanas e grandes cidades, mas esse processo também ocorre em pequenas e médias cidades, em escala nacional e internacional. Nas aglomerações de fronteira, trata-se de um processo que foi intensificado mediante expansão e complexidade da urbanização, mas fluxos e deslocamentos ocorrem desde a gênese das mesmas. Além disso deve-se considerar que, a aglomeração urbana não precisa necessariamente de continuidade do tecido urbano, pois é a intensidade das relações que lhe dá a conceituação como tal.

Diante disso deve-se apontar que, as diferenças entre fronteira e limite são precisas. A fronteira equivale a forças centrífugas, que apontam uma direção para fora e os limites estão orientados para dentro, forças centrípetas. Ao passo que a fronteira pode ser um elemento de integração, o limite constitui-se em elemento de separação (MACHADO, 1998). Desta forma, é através da formação socioespacial, entendida como uma totalidade, que a análise do que é singular a cada país e que, vista como um método, pode evitar comparações descontextualizadas entre os diferentes Estados-nação.

Esse trabalho está dividido em duas partes, exceto introdução e considerações finais. Primeiramente será abordada a gênese e a constituição das cidades pertencentes as três aglomerações urbanas de fronteira, bem como o encaminhamento de suas atividades produtivas. A segunda parte trata das dinâmicas econômicas e sociais nas aglomerações urbanas de fronteira entre 1980 e 2015.

\section{GÊNESE E DESENVOLVIMENTO DAS AGLOMERAÇÕES URBANAS DE FRONTEIRA}

A ocupação da porção sul do Rio Grande do Sul, onde se encontra a cidade de Uruguaiana, foi realizada pelos padres da Companhia de Jesus. A disputa entre Portugal e Espanha pelas terras da América do Sul ocorreu por longo período baseada no Tratado de Tordesilhas, que definia os limites de fronteira, mesmo sem constar precisamente onde encontravam-se esses limites. 
Foram os jesuítas que deram início a criação de gado nesta área, mas é a partir da doação de sesmarias $^{2}$ que, verifica-se o processo de formação das estâncias, criação de cidades e da economia baseada na atividade pastoril; isso ocorreu a partir de 1814, com o objetivo de ocupação do espaço físico. Assim, através das referidas doações, ocorreu a oficialização da grande propriedade rural, que marca a constituição da base fundiária da fronteira oeste gaúcha.

Já o processo de povoamento de Paso de los Libres, de acordo com Schaller (2001), foi difícil, em grande parte por conta da resistência dos indígenas que ali viviam. Soma-se a isso a carência de incentivos políticos e econômicos, repercutindo negativamente no desenvolvimento do local. A pecuária também teve início através do aproveitamento do gado deixado pelos jesuítas, sendo que no século XVIII iniciou-se a criação de gado nas estâncias, a fim de atender a demanda de mercados regionais, especialmente Misiones e Paraguai. A ocupação a partir dos jesuítas promoveu relações econômicas e sociais constantes entre os povoados existentes nas áreas de Uruguaiana e Paso de los Libres ${ }^{3}$.

A partir de 1850 Uruguaiana tornou-se zona comercial, situação que facilitava o contrabando e reduzia os custos das mercadorias para demais cidades do interior. O rio Uruguai foi muito utilizado também pelos comerciantes franceses, ingleses e espanhóis para o transporte de mercadorias que eram adquiridas em Uruguaiana com destino a exportação ou redistribuição para a região (SOARES, 1942).

Atrelado a pecuária, as charqueadas representaram uma atividade fundamental para Uruguaiana. Nesta dinâmica deve-se apontar que, o funcionamento das estâncias estavam relacionadas com a presença do agregado, do peão e do escravo. A composição de classes é importante para a compreensão do processo de formação socioespacial dessa área de fronteira, bem como a continuidade e as mudanças que foram ocorrendo na pecuária.

Uruguaiana foi elevada a condição de sede municipal em 1874 e no ano seguinte foi criada a comarca de Uruguaiana, separando-a de São Borja (PONT, 1983). O comércio da cidade foi favorecido através da instalação da estrada de ferro, que juntamente com a navegação através do rio Uruguai, aproximou a mesma de outros centros urbanos da região do Prata. A ferrovia ligava Barra do Quaraí a Itaqui e foi construída pela empresa inglesa Brazil

\footnotetext{
${ }^{2}$ De acordo com Ferreira (1994), as sesmarias eram lotes de terras incultas ou abandonadas cedidas pela Coroa Portuguesa a pessoas que quisessem cultivá-las, chamadas sesmeiros. O lavrador era obrigado a pagar uma sexta parte dos frutos da terra. Era justamente o dízimo da Ordem de Cristo, esta representada pela Coroa Portuguesa.

${ }^{3}$ Embora neste período as discussões sobre limites e fronteiras houvesse iniciado, o movimento nesta fronteira era constante e o rio não impedia a circulação de pessoas, visto que os estancieiros e os trabalhadores (escravos ou peões) por ali circulavam e relacionavam-se. Trata-se, portanto, do início da estruturação da atividade pecuarista.
} 
Great Southern Railway. Esta ferrovia foi ampliada em 1907, ligando Uruguaiana a Porto Alegre.

Em Paso de los Libres o desenvolvimento da pecuária estava ligado ao crescimento da indústria de charqueadas no Rio Grande do Sul e Uruguai, sendo que, a venda de gado em pé tornou-se um dos mais importantes comércios da província. A mão de obra utilizada nestes trabalhos não era mão de obra negra, mas indígena. Coelho (2008) salienta que, um dos principais motivos da fundação de Paso de los Libres foi a localização estratégica do ponto de vista da comunicação e das relações comerciais com o Brasil. $\mathrm{O}$ rio pouco impedia a circulação entre brasileiros e argentinos (GRIMSON, 2003) e o comércio fronteiriço, principalmente de produtos alimentícios, ocorria diariamente. Pode-se, inclusive, considerar que, ambas cidades estavam inseridas em formações sociais similares: condições naturais, criação de gado, propriedade privada, grandes propriedades, relações servis.

Com o enfraquecimento das charqueadas, no início do século $\mathrm{XX}$, as atividades econômicas de Uruguaiana foram alteradas. A cidade ganhou destaque por meio de suas atividades urbanas; o comércio e os serviços cresceram e diversificaram-se, fato que proporcionou a absorção de grande parte da mão de obra anteriormente ocupada nas charqueadas e atividades relacionadas. O comércio de Paso de los Libres, por sua vez, ganhou destaque a partir da construção da linha férrea Nordeste Argentino, ligando Paso de los Libres a Posadas, no final do século XIX. Foi no final da década de 1920 que teve início o cultivo de arroz em Paso de los Libres. A partir desse período verificou-se uma diferenciação entre as economias de Uruguaiana e Paso de los Libres. Embora tenha ficado evidente uma crise na pecuária de Uruguaiana, verificou-se crescimento nas suas atividades urbanas, fato não ocorrido na mesma proporção na cidade argentina.

Em Uruguaiana, a introdução da rizicultura ocorreu em $1943^{4}$, sendo a modernização da agricultura no Brasil um elemento favorável para o desenvolvimento da rizicultura no município. Através de subsídios e créditos expandiu a cultura, diversificando as atividades agropecuárias do mesmo, anteriormente concentrada na pecuária.

A área onde encontra-se a cidade de Corumbá foi marcada pela chegada dos padres jesuítas no início do século XVII. Assim como ocorrido no Rio Grande do Sul, os missionários introduziram o gado vacum, cavalar, muar e ovino no território matogrossense. Muitos animais ficaram nas antigas povoações, e sem cuidados, os mesmos se espalharam pela região, retornando ao estado selvagem. Mesmo nessas condições, vivendo sem manejo, o

\footnotetext{
${ }^{4}$ Através da compra da primeira fração de terras no município para a instalação de uma colônia de produtores de arroz (colônia rizícola nº 2) pelo Instituto Riograndense do Arroz (IRGA).
} 
número de gado multiplicou-se, constituindo a gênese da pecuária sul-matogrossense (BRAZIL, 2009).

Fundada pelos portugueses em 1778, Corumbá exerceu importante função geopolítica, visto que já em 1775 foi construído o Forte Coimbra, com o intuito de proteção do território contra ataques inimigos. A economia pecuarista que estruturava-se no Mato Grosso do Sul constituia-se em um modelo extensivo e de baixo nivel técnico, contando com força de trabalho indígena (QUEIROZ, 2009). Essas características garantiam um baixo custo de produção do gado e inseriram esta área nos circuitos econômicos nacionais ${ }^{5}$.

No final do século XIX Corumbá foi considerado o terceiro maior porto fluvial da América Latina, ocorrendo também a expansão da cidade e do porto alfandegário. Já a cidade boliviana de Puerto Suárez, teve sua fundação enquanto vila atrelado a uma série de dificuldades e problemas nacionais, elementos que colaboraram para a ausência de investimentos na mesma. Com a implantação da Estrada de Ferro Noroeste do Brasil, ocorreram alterações de eixo na articulação da região, pois a porção sul do Pantanal passou a articular-se com o Sudeste brasileiro através da venda de bois magros, principalmente para São Paulo. Ou seja, a estrada de ferro provocou o desvio de fluxo dos transportes e comunicações da Bacia do Prata para o interior do país e com isso a abrangência desta área foi afetada, pois através da ferrovia as cidades platinas mais desenvolvidas perderam os vínculos com Corumbá.

Como consequência, a partir de 1920 a população de Corumbá passou a diminuir, visto que muitos comerciantes deslocaram-se para outras cidades ou passaram a investir na pecuária. $\mathrm{O}$ enfraquecimento da posição de entreposto comercial de Corumbá também se soma a dificuldade de expansão da mineração, já que neste momento não foi capaz de promover uma nova dinâmica econômica para a cidade. A construção da ferrovia, por outro lado, proporcionou uma importância estratégica para Corumbá, no sentido de tornar-se o principal entreposto comercial com destino a Bolívia. A cidade boliviana de Puerto Quijarro, por sua vez, foi criada apenas na década de 1970, desenvolvendo-se a partir da década de 1990, através do comércio.

No que diz respeito as cidades pertencentes a aglomeração urbana de Foz do Iguaçu deve-se apontar que, quando da chegada da expedição militar, em 1889, a população existente na área era de 324 habitantes, sendo composta predominantemente por argentinos e

\footnotetext{
${ }^{5}$ Os povoadores advindos de Minas Gerais eram pecuaristas que já estavam integrados "[...] desde a segunda metade do século XVIII, ao abastecimento do Rio de Janeiro, e era precisamente em função desse mercado que eles agora se expandiam" (MAMIGONIAN, 1986, p. 47).
} 
paraguaios e apenas nove brasileiros, que viviam da exploração de madeira (WACHOWICZ, 2001). Esta área, durante longo período, manteve-se isolada do país, pois as relações de sua população ocorriam com Posadas, na Argentina.

Puerto Iguazú, na Argentina, foi fundada enquanto vila em 1900, mas tratava-se de uma vila com poucos habitantes e sem atividades econômicas representativas. Em relação ao processo de urbanização, os lotes urbanos começaram a ser vendidos apenas em 1948. Foi a partir da década de 1970, com a construção da Usina de Itaipu que, a cidade de Puerto Iguazú teve crescimento de sua população, alcançando 3.001 habitantes (MANANAL; AREZENO, 2005).

O início da organização de Ciudad del Este se deu no final da década de 1950, ligado a construção da Ponte Internacional da Amizade, tendo seu crescimento atrelado a construção da Usina Hidrelétrica de Itaipu e ao comércio, posteriormente. Na realidade nota-se que, Foz do Iguaçu foi essencial para o início das atividades em Ciudad del Este a partir da década de 1960, contudo não influenciou a cidade argentina. Esta aglomeração foi a que teve seu desenvolvimento mais tardio, na segunda metáde do século XX e profundamente relacionado com a construção de Itaipu.

A próxima parte aborda as atividades econômicas, as relações e as trocas entre as cidades pertencentes a cada uma das aglomerações urbanas de fronteira no período entre 1980 e 2015. Trata-se de um período em que, o setor terciário é fortalecido nas três aglomerações urbanas de fronteira, bem como a ampliação dos agronegócios nas aglomerações de Uruguaiana e Corumbá.

\section{DINÂMICA DAS AGLOMERAÇÕES URBANAS DE FRONTEIRA: 1980 - 2015}

A expansão dos agronegócios brasileiros nos últimos cinquenta anos provocou grandes alterações na estrutura de mercado e na introdução da agropecuária no complexo produtivo da agricultura. A análise produtivista desse processo leva ao erro de considerá-lo apenas sob a ótica da relação mais próxima entre agricultura e indústria, com a crescente intersecção produtiva implantada pelo processo de industrialização advinda da Segunda Revolução Industrial. "Em economias continentais como a brasileira, exigente em irradiar esse processo por largo espaço territorial, essa transformação conforma-se como um autêntico processo de agroindustrialização" (GONÇALVEZ, 2005, p.7). Neste conjunto observa-se a ampliação dos serviços para agropecuária, de preparação e logística, que representam a incorporação de utilidades de beneficiamento, transporte, acesso e armazenagem do produto agrícola. 
O agronegócio está presente em duas das aglomerações urbanas de fronteira em tela. Em Uruguaina, a tabela 01 mostra forte concentração da propriedade da terra, pois em 1980 os pequenos estabelecimentos (com até 100 hectares) representavam 43,5\% do total numérico e apenas 3\% das terras ocupadas. Na contrapartida, os grandes estabelecimentos, com mais de 500 hectares, perfizeram 24\% do número total e 79,58\% do total de terras. Em 1996 e 2006 a situação era relativamente similar, pois os pequenos estabelecimentos alcançaram $48 \%$ do total numérico e $4,1 \%$ da área total. Os grandes estabelecimentos representaram $18 \%$ do total numérico e 77,7\% da área total. Em 1996 (IBGE,1996) ocorreu aumento das terras ocupadas pelos estabelecimentos com até 100 hectares, isso se deu pela inserção de alguns assentamentos rurais.

TABELA 01 - Estrutura dimensional dos estabelecimentos rurais de Uruguaiana:1980/2006 ${ }^{6}$

\begin{tabular}{|c|c|c|c|c|c|c|c|c|}
\hline \multirow{2}{*}{$\begin{array}{c}\text { Grupos } \\
\text { de } \\
\text { área(ha) }\end{array}$} & \multicolumn{2}{|c|}{1980} & Grupos & \multicolumn{2}{|c|}{1996} & Grupos & \multicolumn{2}{|c|}{2006} \\
\hline & Estab & Área & & Estab & Área & & Estab & Área \\
\hline Até 49 & 434 & 7.654 & Até 99 & 438 & 9.226 & Até 49 & 540 & 12.794 \\
\hline 50 a 100 & 160 & 11.674 & 100 a 500 & 416 & 18.014 & 50 a 100 & 261 & 16.248 \\
\hline 101 a 500 & 439 & 111587 & Acima de & 365 & 599877 & 101 a 500 & 575 & 127323 \\
\hline+ de 501 & 332 & 510.319 & 501 & & & + de 501 & 301 & 545.609 \\
\hline Total & 1.365 & 641.234 & Total & 1.219 & 627.117 & Total & 1.667 & 701.974 \\
\hline
\end{tabular}

Fonte: IBGE, Censo Agrícola (1980, 1996, 2006), Sistema Nacional de Cadastro Rural (1997).

Chelotti (2011, p.38) evidência que, sobre as áreas com predomínio de grandes propriedades rurais na Campanha, o processo de modernização não foi capaz de mudar a estrutura fundiária, aliás, concentrou ainda mais. “A grande transformação introduzida pelo processo de modernização nessas áreas foi o desenvolvimento da lavoura capitalista do arroz irrigado, que começou a ser desenvolvida em parceria com a pecuária extensiva". A tabela 02 apresenta os dados referentes a estrutura dimensional dos estabelecimentos rurais de Paso de los Libres em 1988 e $2002^{7}$.

\footnotetext{
${ }^{6}$ Em 2006 algumas mudanças ocorreram na estrutura dimensional dos estabelecimentos rurais de Uruguaiana, pois em 1997 o distrito de Barra do Quarai foi desmembrado de Uruguaiana, tornando-se município, ou seja, algumas alterações em relação a área e quantidade de estabelecimentos rurais está relacionado com esta questão.

${ }^{7} \mathrm{Na}$ Argentina, os censos agropecuários foram realizados nos anos de 1988, 2002 e 2008, sendo este último realizado de forma incompleta em algumas províncias, como Corrientes e Misiones, justificando a opção por não utilizar tais dados.
} 
TABELA 02 - Estrutura dimensional dos estabelecimentos rurais de Paso de los Libres: 1988 e 2002

\begin{tabular}{l|l|l|l|l}
\hline Grupo de área (ha) & \multicolumn{2}{|c|}{$\mathbf{1 9 8 8}$} & \multicolumn{2}{c}{$\mathbf{2 0 0 2}$} \\
\hline & Estab & Área & Estab & Área \\
Até 49 & 203 & 3.366 & 194 & 3.546 \\
50 a 100 & 22 & 2.113 & 38 & 2.865 \\
101 a 500 & 65 & 17.561 & 78 & 21.307 \\
Acima de 501 & 101 & 388.264 & 118 & 410.323 \\
Total & 391 & 409.191 & 428 & 438.041 \\
\hline
\end{tabular}

Os estabelecimentos com até 100 hectares predominam sobre o total nas duas datas; em termos de área representaram 1,33\% e 1,46\% em 1988 e 2002. Os grandes estabelecimentos representavam em números: $25,83 \%$ e $27,57 \%$ dos estabelecimentos em 1988 e 2002, enquanto a área ocupada por esses era de 94,86\% do total em 1988 e de 93,60\% em 2002, ou seja, ocorre forte concentração de terras em Paso de los Libres.

Em relação ao uso da terra em Uruguaiana entre 1980 e 2006, a pastagem, elemento fundamental para o desenvolvimento da pecuária, perdeu 14,35\% de área entre 1980 e 2006, mesmo assim, correspondeu a 79,47\% da área total em 2006 (395.085 ha). Esta diminuição da área de pastagem está relacionada com as técnicas utilizadas na pecuária, especialmente a partir da década de 1990, bem como o desmembramento de Barra do Quarai do território de Uruguaiana. A área de lavoura temporária manteve-se estável, com relativo aumento em 1996 e correspondendo a 15,89\% da área total em 2006 (497.150 ha); a lavoura permanente pouco representa nas atividades agropecuárias do município.

Em Paso de los Libres a área de pastagem corresponde a 86,25\% da área total, que é de 426.386 hectares, fato que evidência a importância da pecuária para o município, enquanto a área destinada a lavoura temporária perdeu 414 hectares entre 1988 e 2002, totalizando 7.812 hectares em 2002. A lavoura permanente, assim como em Uruguaiana, tem pouca representatividade (215 hectares em 2002).

$\mathrm{O}$ arroz destaca-se entre os produtos cultivados em Uruguaiana, com crescimento de $58,9 \%$ entre 1980 e 2006, quando registrou 590.329 toneladas colhidas de 71.124 hectares. A área utilizada, por sua vez, aumentou 15.352 hectares nesse mesmo período ${ }^{8}$. Já a safra de 2015/2016, rendeu 695.044 toneladas de uma área de 83.030 hectares (IRGA, 2016). Segundo o Irga (2016), na safra de 2015/2016, dos 258 estabelecimentos que cultivaram arroz, 150 possuiam área superior a 200 hectares $^{9}$. As demais culturas pouco representaram no conjunto

\footnotetext{
${ }^{8}$ Segundo o IRGA (2016), a área cultivada pode ser alterada (aumentar ou diminuir) de acordo com a disponibilidade de água nas represas.

${ }^{9}$ A divisão completa por grupo de áreas é: 23 estabelecimentos de até 50 hectares, 19 estabelecimentos com área entre 51 e 100 hectares, 66 com área entre 101 e 200 hectares e 150 com área superior a 200 hectares.
} 
da produção agrícola de Uruguaiana, já que a soja, que contou com uma produção de 7.650 toneladas em 1980, passou para uma produção de 480 toneladas em 2006.

$\mathrm{O}$ acesso a políticas de crédito e financiamento foi um dos elementos principais da expansão da agricultura em áreas tradicionais da pecuária. Atrelado a isso tem-se o fato de que, Uruguaiana apresenta uma boa potencialidade de produção, devido ao tipo de solo, de média fertilidade natural e com ótima resposta a utilização de fertilizantes químicos, possuindo também baixa capacidade de infiltração de água, elemento fundamental para a garantia de seu uso e manejo, contando com grande número de mananciais, arroios e rios.

Mesmo não contando com indústrias, em Uruguaiana estão instalados os escritórios das principais marcas, como a Camil, Josepar, Tio João, Ceolin, Prato Fino, Namorado, Zaeli e Pilleco. De acordo com o presidente da Associação dos Arrozeiros (2016), todo o arroz produzido em Uruguaiana sai do município em casca e é beneficiado em outros locais. Neste contexto é importante apontar que, o PIB de Uruguaiana em 2014 foi de R\$ 2.295.349, onde $24 \%$ veio do arroz.

Um elemento fundamental no processo de produção do arroz diz respeito as relações sociais, que em Uruguaiana ocorrem por assalariamento e por contratação temporária. De acordo com o IRGA (2009), para cada 30 hectares cultivados, um posto de trabalho é criado ${ }^{10}$. O presidente da Associação dos Arrozeiros (2016), em entrevista, salienta que, a maior parte dos estabelecimentos contrata pessoal para trabalho temporário no período das safras, contudo, os mesmos mantem alguns trabalhadores e suas famílias no próprio estabelecimento, e além do salário, recebem moradia e participação na produção ${ }^{11}$.

A produção agrícola de Paso de los Libres é basicamente o arroz, pois além deste, foi contabilizada a produção de milho, que em 2002 totalizou 1,6 tonelada de um hectare cultivado (INDEC, 2002). Em relação ao arroz, em 1988 foram colhidas 20.878 toneladas de 9.334 hectares, apresentando queda em 2002, quando foram colhidas 19.965 toneladas de 7.810 hectares. De acordo com Stangaferro (2016), as empresas arrozeiras fecharam quase todas, pois com a ida de produtores brasileiros, especialmente para Mercedes ${ }^{12}$, os processos de produção e comercialização do arroz foram direcionados para outras cidades, onde a produção e beneficiamento do arroz intensificavam-se. Stangaferro (2016) aponta ainda que,

\footnotetext{
${ }^{10}$ Em 2006, de acordo com o Censo Agropecuário, eram 3.757 empregados permanentes e 489 temporários.

${ }^{11} \mathrm{O}$ salário dos trabalhadores fixos (que residem nos estabelecimentos) é de aproximadamente R $\$ 1.800,00$. Além do salário, recebem toda a infraestrutura, e alguns também possuem a participação na produção, que segundo o presidente da Associação dos Arrozeiros (2016), pode chegar a 400 sacas de arroz por safra.

12 Muitos arrozeiros de Uruguaiana e demais cidades da Campanha direcionaram-se para cidades da Argentina, Paraguai e Uruguai para produzir arroz, especialmente a partir da década de 1990 e com objetivo de expandir suas produções.
} 
nunca houve uma organização entre os produtores de arroz de Paso de los Libres, seja através de associações ou cooperativas.

Em relação ao rebanho bovino de Uruguaiana, mesmo sendo o mais importante, tanto em cabeças quanto em estabelecimentos, teve queda de $11,33 \%$ no número de cabeças e de 48\% no número de estabelecimentos entre 1980 e 2006, totalizando 557 estabelecimentos e 368.646 cabeças na última data. Neste sentido é importante destacar que, muitos estabelecimentos dedicam-se concomitantemente a criação de gado e a produção de arroz.

O gado criado na cidade gaúcha é destinado ao corte, no entanto, o abate e o processamento da carne não são realizados no município, visto que o mesmo conta com apenas um frigorífico, que atende a demanda local. De acordo com o presidente da Associação Pecuarista de Uruguaiana (2016), o gado é vendido em pé e abatido em outros municípios, cujo maior comprador é a empresa JBS. No que diz respeito as relações sociais nesta atividade deve-se apontar que, estas permanecem com as mesmas características, ou seja, pouca mão de obra e majoritariamente assalariada. De acordo com o presidente da Associação dos Arrozeiros de Uruguaiana (2016), existe o entendimento, tanto dos criadores de gado quanto dos produtores de arroz, que a rizicultura tornou-se uma atividade mais atrativa e rentável em comparação a pecuária.

O rebanho de maior representatividade em Paso de los Libres é o bovino, que em 2002 contava com 237.086 cabeças e 382 estabelecimentos. Nesta mesma data, o município era o quinto colocado em número de cabeça de gado da província, contribuindo com 6,55\% do total de animais de Corrientes ${ }^{13}$. Em Corrientes destaca-se a criação de gado de cria, onde 68,7\% são constuidos por animais da raça Zebu, seguido de 23,7\% de raças européias, 5,1\% índicas e $2,5 \%$ criolas.

Marcarrein et al (2006) evidenciam que, a província apresenta uma influência periférica na economia pecuarista da Argentina. Isso se dá pelos baixos indíces produtivos, ligados principalmente “[...] en planteos de explotación extensivos pastoriles de baja eficiencia. En general la eficiencia productiva de la cría vacuna, rasgo determinante de la producción pecuaria provincial, se encuentra dominada por bajos rendimientos, no superando el 48\% la tasa de marcación de la mayoría de los rodeos” (MACARREIN, 2006, p. 15). Paso

\footnotetext{
13 "Conforme a estimaciones de la Encuesta Nacional Agropecuaria 2001, con datos recogidos al 30 de junio de ese año, Corrientes tiene un total de 3.720 .100 bovinos, lo que representa el $7.6 \%$ del stock bovino del país, mientras que las existencias totales de ganado Bovino en ese ámbito alcanzaron a 48.851 .000 cabezas" (MACARREIN, 2006, p. 16).
} 
de los Libres conta com apenas um frigorífico, o Frigorífico Maen S.A, que é responsável pela carne consumida no município, com 13.514 cabeças abatidas em 2009.

A rizicultura tornou-se, ao longo dos anos, a principal atividade agropecuária de Uruguaiana, com intensos investimentos tecnológicos, e mesmo não havendo indústrias beneficiadoras no município, a atividade foi modernizada no decorrer do tempo. Em Paso de los Libres a situação foi inversa, ou seja, mesmo com alguma tecnologia empregada, não houve incremento e a cultura perdeu importância ao longo tempo.

Em relação ao agronegócio na aglomeração urbana de Corumbá, em 1980, dos 1.082 estabelecimentos rurais, 718 possuiam área superior a 501 hectares, ou seja, 66,35\% do total das propriedades do município em uma área de 5.587 .000 hectares, enquanto os estabelecimentos com área inferior a 500 hectares perfaziam 17,28\% dos estabelecimentos e área total.

TABELA 3 - Estrutura dimensional dos estabelecimentos rurais de Corumbá: 1980/2006

\begin{tabular}{|c|c|c|c|c|c|c|c|c|}
\hline & \multicolumn{2}{|c|}{1980} & \multicolumn{3}{|c|}{1996} & \multicolumn{3}{|c|}{2006} \\
\hline $\begin{array}{l}\text { Grupos de } \\
\text { Área (ha) }\end{array}$ & Estab & Área & $\begin{array}{l}\text { Grupos de } \\
\text { área (ha) }\end{array}$ & Estab & Área & $\begin{array}{l}\text { Grupos de } \\
\text { Área (ha) }\end{array}$ & Estab & Área \\
\hline Até 49 & 187 & 3.124 & Até 99 & 455 & 1.510 .233 & Até 49 & 992 & 6.984 \\
\hline 50 a 100 & 54 & 3.568 & 100 a 500 & 89 & 838.507 & 50 a 100 & 71 & 2.883 \\
\hline 101 a 500 & 123 & 29.130 & Mais de 501 & 665 & 2.859 .027 & 101 a 500 & 69 & 24.053 \\
\hline+ de 501 & 718 & 5.587 .000 & & & & + de 501 & 521 & 6.634 .769 \\
\hline Total & 1.082 & 5.622 .822 & & 1.209 & 5.207 .767 & & 1.653 & 6.668 .690 \\
\hline
\end{tabular}

Fonte: IBGE, Censo Agrícola (1980, 1996, 2006).

Em 2006 nota-se alterações, especialmente em relação a distribuição das propriedades, ou seja, embora as grandes propriedades continuem representando a maior parte da área destinada as propriedades rurais (99\% da área), as propriedades com área inferior a 50 hectares tiveram um grande incremento, já que nesta contagem eram 992 estabelecimentos em uma área de 6.984 hectares. O estrato de área entre 50 e 100 hectares possuía 71 estabelecimentos em 2.883 hectares e 69 estabelecimentos constituíam o estrato de área entre 101 e 500 hectares.

Estes dados confirmam que, a concentração fundiária, de acordo com Araujo (2006), permanece como a característica mais marcante da organização do espaço pantaneiro. Todavia, há mudanças no sentido da diminuição do tamanho médio das propriedades, seja pela venda da terra ou pelo desmembramento por herança. Outro elemento importante diz respeito ao aumento de $81,15 \%$ (entre 1980 e 2006) dos estabelecimentos com área inferior a 50 hectares. Trata-se da inserção da pequena propriedade através de assentamentos rurais. Entre 1986 e 1999 foram criados seis assentamentos rurais no município de Corumbá. Nestes 
estabelecimentos são desenvolvidas atividades agrícolas e a bovinocultura de leite (EMBRAPA, 2002).

Na Bolívia, o primeiro censo agropecuário foi realizado em 2013 e diferente das pesquisas realizadas pelo IBGE, o Instituto Nacional de Estadísticas - INE, não fez a distinção das propriedades rurais por grupos de área. Desta forma, o INE aponta que, em 2013 a superfície rural de Puerto Suárez era de 1.260.691 hectares, divididos em 599 estabelecimentos. Em Puerto Quijarro, no mesmo ano, a superfície rural era de 143.763 hectares e 426 estabelecimentos rurais. A área destinada aos estabelecimentos rurais de Puerto Quijarro representava apenas $11,35 \%$ da área rural de Puerto Suárez, área bastante restrita para a agropecuária, tendo sua economia centrada no comércio.

Em relação ao uso da terra em Corumbá verifica-se que, entre 1980 e 2006 ocorreu diminuição de $73,39 \%$ na área destinada a lavoura temporária, que era de 6.365 hectares em 1980. O mesmo ocorreu com a lavoura permanente, que em 2006 possuia apenas 364 hectares cultivados. A pastagem ocupa maior parcela de terras em Corumbá, cuja área praticamente manteve-se entre 1980 e 2006 (3.657.382 hectares em 2006).

No que diz respeito a utilização da terra nos municípios bolivianos de Puerto Suárez e Puerto Quijarro nota-se que, assim como em Corumbá, a agricultura é pouco praticada. A área destinada para a lavoura permanente em 2013 era de 1.695 hectares em Puerto Suárez e 107 em Puerto Quijarro, enquanto a lavoura temporária contava com 47 hectares em Puerto Suárez e 32 em Puerto Quijarro. A pastagem é o segmento que mais utiliza terra nos dois municípios bolivianos, mesmo que, a área destinada para a pecuária em Puerto Suárez (91.074 ha) represente apenas $24,88 \%$ da área destinada a mesma atividade em Corumbá. Em Puerto Quijarro a área de pastagem corresponde a 15.097 hectares.

Dentre as atividades agropecuárias, a pecuária bovina é a mais importante e que insere Corumbá no agronegócio da carne. Entre 1980 e 2006 o número de estabelecimentos com criação de gado aumentou $6,06 \%$ e o número de cabeças aumentou 22,72\%. O rebanho bovino de Corumbá é formado principalmente por gado Zebu, com distintos graus de sangue e predomínio da raça Nelore, que por suas características de precocidade e rusticidade, teve uma boa adaptação as condições físicas do Pantanal. No que diz respeito a formação social proveniente desta atividade, Araujo (2006, p.134) explica que “ As grandes fazendas, que são propriedades de grupos econômicos mais poderosos ou de empresários externos à região, geralmente do sudeste, organizam-se dentro dos moldes empresariais, possuindo superintendentes, diretores administrativos, assessores, supervisores, gerentes, veterinários, técnicos em agropecuária, etc”. Neste contexto, o presidente do Sindicato Rural de Corumbá 
(2016) acrescenta que, no município, uma média de 2 mil pessoas são empregadas de forma direta e/ou indireta pela pecuária bovina. A maior parte do gado criado no município é comprado pela JBS, sendo efetuada diretamente com o criador, além dos leilões, que ocorrem mensalmente. A pecuária foi responsável por $6 \%$ da composição do PIB do município em 2014 (IBGE).

Em relação a atividade pecuária nos municípios bolivianos de Puerto Suárez e Puerto Quijarro, em 2013 o rebanho de maior representatividade era o bovino, contando com 50.941 cabeças em Puerto Suárez e 8.384 em Puerto Quijarro. A criação de animais nesta porção da Bolívia é destinada apenas ao consumo local. Candia e Antelo (2005) apontam que, a produção agropecuária boliviana é limitada, com mão de obra pouco qualificada e sem estruturas de apoio a promoção das exportações, além do transporte ser de alto custo e o crédito de difícil acesso.

No que diz respeito a estrutura dimensional dos estabelecimentos rurais de Foz do Iguaçu, esta é bem distinta das verificadas em Uruguaiana e Corumbá.; trata-se de outra formação socioespacial. Em 1980, 87\% dos estabelecimentos encontravam-se no estrato de até 49 hectares, enquanto as grandes propriedades eram representadas por apenas 10 estabelecimentos. O representante do Sindicato Rural de Foz do Iguaçu (2016) explicita que, a agropecuária do município é formada por pequenos produtores, que abastecem o mercado local.

A estrutura dimensional dos estabelecimentos rurais de Ciudad del Este mantem características similares aos de Foz do Iguaçu, mas com menores números. Em 2008 existiam 441 estabelecimentos rurais no município, sendo $65,75 \%$ representados por pequenas propriedades, e nenhuma propriedade com área superior a 501 hectares, frisando a formação social da pequena propriedade. Assim como em Foz do Iguaçu e Ciudad del Este, as pequenas propriedades predominam em Puerto Iguazú. No entanto, em relação a área ocupada, há predomínio daqueles acima de 501 hectares. A pecuária, assim como a agricultura, pouco representa nos municípios pertencentes a esta aglomeração.

De modo geral os dados confirmam que, tanto a agricultura quanto a pecuária pouco representam na economia de Foz do Iguaçu, Ciudad del Este e Puerto Iguazú. São municípios com formação socioespacial da pequena propriedade e que, além de não fazerem parte de cadeias do agronegócio, possuem área rural restrita e constítuida por pequenos agricultores familiares. Por outro lado, tanto Corumbá como Uruguaiana participam dos agronegócios brasileiros, Corumbá no agronegócio da carne e Uruguaiana nos agronegócios da carne e do 
arroz, assim como Paso de los Libres participa, ativamente do agronegócio da carne e em menor proporção, do agronegócio do arroz, na Argentina.

A indústria, nas cidades das aglomerações urbanas em estudo, não se coloca como significativa do ponto de vista do número de estabelecimentos e trabalhadores, embora a participação da indústria no PIB de Corumbá e especialmente de Foz do Iguaçu, seja importante: $16 \%$ do PIB de Corumbá foi composto pela indústria em 2014, enquanto o PIB de Foz do Iguaçu contou com $65 \%$ da indústria no mesmo ano. Uruguaiana, contudo, teve $9 \%$ de participação da indústria na formação de seu PIB (IBGE, 2015). Em Corumbá destacam-se as mineradoras, e em Foz do Iguaçu, o grande peso no PIB industrial vem da produção de energia de Itaipu.

Em relação ao setor industrial de Corumbá, em 2014 existiam 130 estabelecimentos e 2.698 trabalhadores (RAIS/MTE, 2014). A metalurgia representou 38,18\% e 10,12\% de trabalhadores e estabelecimentos, respectivamente. A empresa Vetorial é a maior delas e especializada na produção de ferro gusa, com uma média de 370 mil toneladas produzidas por ano. No ramo de produtos minerais não metálicos, o segundo mais importante, destaque para o Grupo Votorantim ${ }^{14}$, que conta com uma unidade em Corumbá - Cimentos Itaú - e outra em Puerto Quijarro - Itacamba Cementos. A Votorantim Cimentos em Corumbá produz 300 mil toneladas anualmente, com operação 24 horas por dia e com a geração de 300 empregos. Os demais ramos são compostos por pequenas unidades produtivas, com mercado local e/ou regional; exceto a mineração, que é o ramo de maior importância para Corumbá.

Até 2008 estavam instaladas em Corumbá e Ladário as seguintes empresas de exploração de minério de ferro: Corumbá Mineração (COMIN), do Grupo Vetorial; a Urucum Mineração SA. (UMSA), da Vale (VALE); Mineração Corumbaense Reunida (MCR), pertencente à multinacional Rio Tinto do Brasil (RTB); Mineração e Metálicos do Brasil Ltda. (MMX), do Grupo EBX e Mineração Pirâmide Participações (MPP) (LIMA, 2008). Entretanto, com a crise de 2008/2009, a Rio Tinto do Brasil vendeu suas operações no Mato Grosso do Sul para a Vale e a MMX vendeu seu mais importante investimento - a MMX metálicos, para o Grupo Vetorial, mantendo apenas a mina. A partir de 2009, a Vale, já privatizada, detém $90 \%$ da produção mineral de Corumbá.

A Vale tornou-se a única empresa a explorar o manganês em Corumbá. Em 2013 a produção nacional foi de 2,8 milhões de toneladas, e deste montante, 14,6\% diz respeito a produção do Mato Grosso do Sul (DNPM, 2014). Em relação a produção brasileira de minério

\footnotetext{
${ }^{14}$ A Votorantim Cimentos é uma das maiores indústrias de cimento, concreto, agregados e argamassas do mundo, com uma receita de R $\$ 12.9$ bilhões em 2014. Possui unidades em 13 países.
} 
de ferro, em 2013 foram 386,3 milhões de toneladas, sendo que, desse montante $2 \%$ diz respeito ao minério de ferro do Mato Grosso do Sul. O número de empregos gerados na exploração do minério de ferro em Corumbá em 2008 foi de 1.253, sendo 709 empregos diretos e 544 empregos indiretos. Na extração do manganês, neste mesmo ano, foram 459 empregos diretos e 354 indiretos, totalizando 813 empregos (DNPM, 2013, 2014).

No que diz respeito a exploração de minérios da Morraria de Mutúm ${ }^{15}$, no município de Puerto Suárez, não há nenhuma empresa realizando tais atividades, visto os impasses em relação as exigências do país para a realização da mesma ${ }^{16}$. Exceto a unidade da Votorantim Cimentos em Puerto Quijarro, que contou em 2014 com uma produção de 170.000 toneladas, as cidades bolivianas não contam com outras indústrias de médio e/ou grande porte.

Em Uruguaiana o destaque é a construção civil, com crescimento de 91,14\% em quase 30 anos. Assim como na maior parte das cidades do Brasil, Uruguaiana vivenciou o crescimento do setor, que passou de 14 estabelecimentos em 1985 para 158 em 2014, enquanto os empregos saltaram de 285 em 1985 para 739 em 2014. Uruguaiana conta com pequenas indústrias, as quais pouco representam no âmbito local e/ou regional. Em Paso de los Libres não há registro de indústrias de grande porte e que sejam importantes do ponto de vista do número de trabalhadores.

Em Foz do Iguaçu, destaque para o setor alimentício, com crescimento de $70 \%$ no número de estabelecimentos e de 83,16\% no número de trabalhadores, entre 1985 e 2014. De acordo com RAIS/MTE (2014), eram 65 estabelecimentos e 558 trabalhadores na última data. A construção civil foi o setor que registou crescimento em todos os períodos. Esse crescimento justifica-se, primeiramente pela necessidade de construção de moradias e toda infraestrutura a partir da construção de Itaipu, posteriormente pelo desenvolvimento do turismo, e mais recentemente com o projeto habitacional lançado no governo Lula, Minha Casa Minha Vida. Neste sentido os dados apresentam crescimento de 95,57\% no número de estabelecimentos e de 73,6\% de trabalhadores entre 1985 e 2014, com 451 estabelecimentos e 3.500 trabalhadores ${ }^{17}$ (RAIS/MTE, 2014).

\footnotetext{
15 Trata-se de uma das maiores jazidas de minério de ferro do mundo, com uma média de 40.205 milhões de toneladas.

16 Em 2007 o governo federal assinou contrato com a empresa indiana Jindal Steel e Power, com previsão de investimentos na ordem de US\$ 2,1 bilhões, construção de fornos e de uma termoelétrica; o contrato foi revisto e não teve prosseguimento.

${ }^{17}$ Em relação aos trabalhadores é fundamental apontar que, estes números são números oficiais e que, a parte isso, um grande contingente de trabalhadores paraguaios compõem a mão de obra da construção civil de Foz do Iguaçu. Trata-se de um processo que vem ocorrendo desde o final da década de 1990, quando do início da decadência do período dos sacoleiros no Paraguai. Com a falta de emprego em Ciudad del Este, atrelado ao crescimento da construção civil em Foz do Iguaçu, um grande número de paraguaios começou a atravessar a fronteira para buscar ocupação.
} 
Os dados do Ministério do Trabalho e Segurança da Argentina mostram que, em 2014 existiam em Puerto Iguazú 36 indústrias e 469 trabalhadores. Entre estas indústrias existem algumas no ramo madeireiro, com destaque para a Maderas de la Mesopotamia, inaugurada em 2012 e especializada na fabricação de pellets $^{18}$. Em Ciudad del Este os censos econômicos demonstram que, a indústria de produtos metálicos é a mais representativa, com 1.477 trabalhadores e 257 estabelecimentos em 2010, seguido da indústria madeireira e móveis, que no mesmo período contava com 246 estabelecimentos e 874 trabalhadores. De forma geral, as aglomerações urbanas aqui estudadas apresentam fraqueza industrial.

A construção de Itaipu tem papel crucial para o entendimento do setor terciário da aglomeração urbana de Foz do Iguaçu, entre outros aspectos, pelo aumento populacional que as cidades tiveram a partir dai. Nesta perspectiva ocorreu um intenso incremento do comércio de fronteira, principalmente de Ciudad del Este para Foz do Iguaçu, onde muitos brasileiros passaram a buscar produtos na primeira para serem revendidos.

Foi, portanto, a partir desse momento que, as atividades comerciais de Foz do Iguaçu, Ciudad del Este e Puerto Iguazú ganham novos elementos e maior importância. Em 1985 existiam em Foz do Iguaçu 897 estabelecimentos comerciais, sendo 703 varejistas e 194 atacadistas, somavam 5.567 empregos (RAIS, MTE). Segundo Prado (2003), na década de 1980 Ciudad del Este chegou a comercializar U\$ 12 bilhões, perdendo apenas para Hong Kong e Miami. No início da década de 1990 a cidade recebeu cerca de 3 milhões de pessoas, entretanto, com a abertura comercial iniciada pelo governo Collor no Brasil e com a redução da isenção de impostos sobre mercadorias estrangeiras a partir de 1995, teve início a redução do comércio de Ciudad del Este.

O comércio varejista de Ciudad del Este teve crescimento de 12,16\% em relação aos trabalhadores e 4,75\% para estabelecimentos entre 2000 e 2010; eram 11.508 estabelecimentos e 33.889 trabalhadores em 2010. O comércio atacadista, por sua vez, contava com 926 estabelecimentos e 8.402 trabalhadores em 2010 (DEGEEC, 2011). Os dados apresentados sobre o comércio em Ciudad del Este são dados formais, sabe-se, através da literatura e através de levantamentos de campo que, o número de ocupações sem carteira assinada pode facilmente ultrapassar o número de empregos formais.

Sobre Puerto Iguazú Dreyfus (2007) explicita que, a economia do município é periférica para a Argentina, tendo como principal atividade econômica o turismo. Em relação ao comércio existente na cidade, o Ministério do Trabalho, Emprego e Segurança Social

\footnotetext{
${ }^{18}$ Trata-se de um tipo de biocombustível feito a partir da serragem e lascas de madeira. As fabricadas em Puerto Iguazú possuem entre 6 e 8 milímetros e são utilizadas em caldeiras industriais e domésticas (MADERAS DE LA MESOPOTAMIA, 2017).
} 
(2016) mostra que, em 2014 existiam em Puerto Iguazú 364 estabelecimentos de comércio e reparação e a geração de 1.993 empregos. Deve-se considerar as diferenças cambiais entre as moedas de cada país como elemento essencial para a dinâmica econômica das aglomerações de fronteira. Neste sentido, desde o início de 2015 é intensa a presença da população argentina no comércio de Foz do Iguaçu.

De forma geral verifica-se que, o comércio criado nesta aglomeração de fronteira tem profundas relações com a construção de Itaipu, pois foi a partir do início das obras que, milhares de pessoas direcionaram-se para as cidades de Foz do Iguaçu e Ciudad del Este. Diante disso e considerando que o terciário é o maior gerador de empregos nesta aglomeração urbana, deve-se ressaltar que, entre 1985 e 2014 quase todos os segmentos de serviços tiveram expansão no número de trabalhadores e estabelecimentos, com exceção das instituições de crédito, seguros e capitalização, que teve forte redução no número de trabalhadores. Dentre todos, destaque para aqueles de alojamento e alimentação, reparação e manutenção, que teve constante aumento, muito ligado a atividade turística através de hotéis, restaurantes, agências de turismo, transportes, etc.

Estes passaram de 326 estabelecimentos e 4.787 trabalhadores em 1985 para 1.122 estabelecimentos e 12.186 trabalhadores em 2014. O segundo segmento em destaque é a administração pública direta e autárquicas, até certo ponto vinculada ao próprio crescimento populacional de Foz do Iguaçu (população total de 263.915 e $99 \%$ de taxa de urbanização em 2015) (IBGE, 2015). O setor de transporte e comunicação também apresentou expansão para estabelecimentos e trabalhadores, vinculado ao turismo e ao Mercosul.

Os dados referentes aos serviços em Ciudad del Este mostram que, o setor que mais cresceu entre 2000 e 2010 foi o de alimentação, que teve crescimento de 20,87\% no número de estabelecimentos e de 24,96\% no número de trabalhadores, compostos por 1.270 estabelecimentos e 3.534 trabalhadores em 2010 (DEEGEC, 2011). Os setores mais dinâmicos em serviços de Puerto Iguazú são aqueles relacionados a atividade turística, com destaque para hotéis e restaurantes, aqui apresentados de forma conjunta, apresentando em 2014, 150 unidades e 1.742 trabalhadores.

Os dados apresentados acerca da estrutura de comércio e serviço nesta aglomeração urbana de fronteira mostram que, ocorre uma intensa e constante dinâmica entre as cidades. No entanto, ocorre um distanciamento maior entre Foz do Iguaçu e Puerto Iguazú, se comparada com a aproximação de Foz do Iguaçu e Ciudad del Este. Além disso, existe maior controle aduaneiro por parte do Estado argentino, dos veículos de passeio, cargas e turismo. 
Foi apenas em 2010, com o Mercosul já estabelecido, que nota-se crescimento nos segmentos do comércio de Uruguaiana. O comércio varejista apresentou crescimento de $26,3 \%$ no número de estabelecimentos e de 22,07\% no número de trabalhadores entre 1985 e 2010 (959 estabelecimentos e 6.039 trabalhadores em 2010) (RAIS, MTE, 2014). Da mesma forma, o comércio atacadista apresentou crescimento, com 79 estabelecimentos e 369 trabalhadores. Em Paso de los Libres, no ano de 2014, existiam 221 estabelecimentos de comércio e reparação e 1.304 trabalhadores. Os fluxos comerciais entre Paso de los Libres e Uruguaiana são semelhantes aqueles que ocorrem entre Foz do Iguaçu e Puerto Iguazú e estão intimamente relacionados com o câmbio.

Dos setores de serviço, o que mais cresceu foi o de transporte e comunicação, com 365 estabelecimentos e 2.507 trabalhadores em 2014 (RAIS/MTE, 2014). O crescimento dos serviços de transporte está intimamente relacionado com o Mercosul e com a construção da Estação Aduaneira. Os serviços médicos, odontológicos e veterinários e os de educação, não apresentaram crescimento notável no período. Em Paso de los Libres os serviços mais importantes são os setores de transporte, armazenamento e comunicação e as atividades imobiliárias, empresariais e de aluguel, que juntos, contam com 669 trabalhadores. Uruguaiana e Paso de los Libres tem como característica a expressividade do setor terciário, constituindo-se importante empregador formal da população das cidades, e correspondendo, em ambas, a cerca de 60\% do mercado de trabalho formal (ADIALA, 2005). As interações entre as duas cidades estão fundamentalmente relacionadas com as vantagens econômicas proporcionadas nos momentos de variação cambial.

Sobre a dinâmica comercial de Corumbá, verifica-se o contínuo aumento de estabelecimentos e trabalhadores no comércio varejista, que passou de 250 estabelecimentos e 1.325 trabalhadores em 1985 para 534 estabelecimentos e 3.348 trabalhadores em 2014 (RAIS/MTE, 2014). O comércio atacadista, no entanto, apresentou diminuição no número de estabecimentos, passando de 77 para 44 no mesmo período, o número de trabalhadores manteve-se estável, com 449 em 2014.

O INE (2012) aponta que, em Puerto Quijarro, 42,4\% da população trabalha no setor de comércio e serviços, enquanto em Puerto Suárez, 23,4\% da população está vinculada ao comércio e/ou serviços. O comércio nas cidades bolivianas, especialmente em Puerto Quijarro, teve grande impulso a partir da década de 1990. Neste período, a migração para Puerto Suárez e Puerto Quijarro intensificou-se, em função da atração exercida pelo comércio varejista com o Brasil. Ainda na década de 1990, foi criada em Puerto Quijarro, a Zona Franca Central Aguirre, também conhecida como shopping China, com lojas que ofereciam 
equipamentos eletrônicos, bebidas, perfumes e demais produtos importados, o qual empregou muitos corumbaenses.

Assim como nas demais aglomerações urbanas de fronteira, as mudanças cambiais são fundamentais nas relações comerciais entre as cidades; em entrevista realizada em 2015 com comerciantes e gerentes de supermercados e lojas de eletrodomésticos, notou-se considerável aumento na procura e no consumo dos bolivianos.

Segundo entrevista realizada, Céspedes (2015) aponta que, até outubro de 2015, cerca de $65 \%$ dos funcionários do shopping China, em Puerto Quijarro, haviam sido dispensados. O comércio de Puerto Suárez e Puerto Quijarro, de forma geral, tem diminuido o número de trabalhadores ou fechando seus estabelecimentos. Como visto anteriormente, $42 \%$ da população de Puerto Quijarro trabalha no comércio e nos poucos serviços disponíveis, isso numa contagem oficial, ou seja, o número de pessoas envolvidas no comércio do município é maior. Essa diminuição também está relacionada com o fechamento da Zona Franca, que empregava grande número da população dos municípios bolivianos.

Em Corumbá os serviços que mais aumentaram entre 1985 e 2014 foram os relacionados a Administração pública direta e autárquica, que contou com crescimento de 66,26\% no número de trabalhadores e diminuição de mais da metade dos estabelecimentos, totalizando quatro estabelecimentos e 3.526 trabalhadores em 2014 (RAIS/MTE, 2014). Também com crescimento, o setor de transportes e comunicações registrou 61,62\% e 79,85\% de crescimento no número de trabalhadores e estabelecimentos, respectivamente, ou seja, 129 estabelecimentos e 1.503 trabalhadores. O único setor que apresentou diminuição foi o de instituições de crédito, seguros e capitalização.

A respeito dos serviços de educação é importante explicitar que, as escolas públicas e particulares de Corumbá são muito frequentadas por bolivianos. Tanto no Brasil quanto na Bolívia a educação básica é gratuita, contudo o fluxo para o estudo no ensino fundamental e médio só ocorre no sentido Bolívia- Brasil. Silva (2012) explicita que, em 2011 cerca de 600 alunos bolivianos estudavam na rede pública de Corumbá, que neste período contava com 18.000 estudantes. É no ensino superior, contudo, que nota-se maior interação. Corumbá conta com duas instituições de ensino superior privadas e uma pública, a Universidade Federal do Mato Grosso do Sul (UFMS); em todas elas existem bolivianos matriculados.

Desta forma, entre os serviços existentes em Corumbá e em Puerto Quijarro, destacam-se aqueles direcionados ao transporte de mercadorias na Estação Aduaneira de 
Corumbá $^{19}$. O setor de transporte destaca-se entre os serviços nesta área de fronteira, especialmente pela sua importância no transporte de cargas, seja por rodovia ou hidrovia.

De forma geral, nas três aglomerações urbanas de fronteira o terciário foi o setor que mais possibilitou relações de troca e fluxos entre as cidades, ou seja, é através do comércio e dos serviços que ocorrem os deslocamentos entre as populações do Brasil, da Argentina, do Paraguai e da Bolívia.

\section{CONSIDERAÇÕES FINAIS}

A dinâmica econômica de cada aglomeração urbana de fronteira mostra que, estas vinculam-se à dinâmica nacional mediante suas especificidades. Em outros termos, a formação socioespacial na área da aglomeração urbana de Corumbá foi marcada inicialmente pelas grandes propriedades, desenvolvendo atividades pecuaristas (como resultado do aproveitamento das condições naturais) para atendimento de demandas internas do Brasil. Decorre ainda de sua posição, a importante atividade comercial através do transporte fluvial, bem cmo seu papel no controle da fronteira com a Bolívia, a exercer papel de comando das atividades econômicas para as cidades e municípios bolivianos.

Em Uruguaiana também se realizou uma formação socioespacial com base na grande propriedade e pecuária bovina, mas cujas condições naturais são distintas daquelas presentes em Corumbá. A partir da pecuária foi possível a transformação da carne em charque, como mecanismo de atendimento de demandas internas do mercado consumidor. Em Paso de los Libres a pecuária ocorria com vistas ao envio do gado para o Brasil e Uruguai. É a partir dai que, as diferenças econômicas entre as cidades da aglomeração urbana de Uruguaiana passam a ser acentuadas, pois além da intensificação do comércio na cidade gaúcha, a construção das ferrovias, no período em que tem início a industrialização brasileira, foi fundamental para o aprofundamento das relações de Uruguaiana com o restante do país e com a Argentina. Somase a essa diferenciação o fato de Uruguaiana ter fortalecido sua economia através da riziculuta, o que não se deu na mesma intensidade em Paso de los Libres.

A construção de Itaipu, enquanto ação estatal, foi responsável por um conjunto de mudanças em toda a aglomeração urbana de Foz do Iguaçu, a começar pelo grande crescimento populacional da cidade, seguido do crescimento e fortalecimento do comércio e dos serviços, pelo próprio desenvolvimento do comércio de Ciudad del Este, entre outros.

\footnotetext{
${ }^{19}$ Até o ano de 2013 os produtos importados entravam sem controle na Bolívia. É neste mesmo ano que foi criada a ACI - Área de Controle Integrado, que concentram-se tanto a brasileira quanto a boliviana no Porto Seco de Corumbá.
} 
Sobre essa dinâmica de fronteira, verificou-se que, os espaços fronteiriços são animados por dois tipos de fluxos econômicos. Uns de ordem estrutural e praticamente permanentes, consistindo na troca de bens, serviços e informações entre cidades com características distintas e outros de ordem conjuntural, que explicam-se pelas flutuações monetárias e por variações dos mercados de produtos agrícolas. Outro elemento importante diz respeito as diferenças, em muitos momentos perceptíveis, no descompasso entre o desenvolvimento econômimo do centro nacional e as dinâmicas estabelecidas nas aglomerações urbanas de fronteira.

\section{REFERENCIAS BIBLIOGRÁFICAS}

ADIALA, C, S, M, de. Cidades no limite internacional e a influência de políticas públicas oriundas de escalas de ação variadas: Uruguaiana e Santana do Livramento - RS. X Encontro de Geógrafos da América Latina. Anais... São Paulo, 2005.

ARAUJO, A, P, C, de. Pantanal: um espaço em transformação. Tese (Doutorado em Geografia), 2006. Universidade Federal do Rio de Janeiro, Rio de Janeiro, 2006.

BEAUJEU-GARNIER J; CHABOT, G. Tratado de geografía urbana, n.711. Buenos Aires, 1970.

BRASIL. Ministério da Integração Nacional. Proposta de reestruturação do Programa de Desenvolvimento da Faixa de Fronteira. Secretaria de Programas Regionais, Programa de Desenvolvimento da Faixa de Fronteira, Brasília: MIN, 2005.

BRAZIL, M. C. Sobre os campos de vacaria do sul de Mato Grosso: considerações sobre terra e escravidão [1830-1889]. In: MAESTRI, M e BRAZIL, M. C. Peões, vaqueiros, cativos campeiros: estudos sobre a economia pastoril no Brasil. Passo Fundo: Editora Passo Fundo, 2009.

CANDIA, F; ANTELO, E. Políticas sectoriales para promover la competitividad en Bolivia. In: Políticas Sectoriales en la Región Andina. Corporación Andina de Fomento, La Paz, 2005.

CHELOTTI, M, C. Produção desigual do espaço e dinâmica regional da agropecuária na Campanha Gaúcha (Brasil). Observatorium, v.2, n.6, Uberlândia , abr, 2011.

DREYFUS, P. La Triple Frontera: zona de encuentros y desencuentros. In: HOFMEISTER, W.; ROJAS, F.; SOLIS, J. G. (Org.). La percepción de Brasil en el contexto internacional: perspectivas y desafios. Rio de Janeiro: Konrad-Adenauer-Stiftung, 2007.

EMBRAPA. Considerações sobre a saída de bovinos do município de Corumbá. Circular técnica, Corumbá, 2002.

FERREIRA, L. P. Curso de direito agrário. São Paulo: Saraiva,1994.

GONÇALVEZ, J, S. Agricultura sob a égide do capital financeiro: passo rumo ao aprofundamento do desenvolvimento dos agronegócios. Informações Econômicas, v.35, n.4, São Paulo, 2005.

GRIMSON, A. La nación e sus limites. Contrabandistas y exilados en la frontera ArgentinaBrasil. Barcelona: Ed Gedisa, 2003.

LIMA. L, M. Avaliação Ambiental Estratégica (AAE) do polo minero-industrial de Corumbá. Rio de Janeiro: LIMA/COPPE/UFRJ, 2008.

MACARREIN, O, F. et al. La evolución ganadera de la provincia de Corrientes. Universidad Nacional del Nordeste. Comunicaciones Científicas y Tecnológicas, Corrientes, 2006. 
MACHADO, L, O. Limites, Fronteiras, Redes. In: STROHAECKER, T, et al. (Org.). Fronteiras e Espaço Global. Porto Alegre: AGB-Seção Porto Alegre, 1998.

MAMIGONIAN, A. Inserção de Mato Grosso ao mercado nacional e a gênese de Corumbá. Geosul , n. 1, Florianópolis, 1986.

MANANAL, M; ARZENO, M. Territorio y poder em la globalizacion: disputas por la tierra em ela nordeste de Misiones, Argentina. Revista Paraguaya de Sociologia, n.138, ano 48, Assuncion, 2005.

PONT, R. Campos realengos: formação da fronteira sudoeste do Rio Grande do Sul. Porto Alegre: Renascença, 1983.

QUEIROZ, P, R, C. Uma esquina nos confins do Brasil: o Sul do Mato Grosso Colonial e suas vias de comunicação (projetos e realidades). Fronteiras, v.11, n.19, Dourados, 2009.

SCHALLER, E, C. El proceso de distribuición de la tierra em la província de Corrientes (1588-1895) In: Anuario del CEH, n.1, Resistencia, 2001.

SOARES, M, A. Uruguaiana: um século de história (1843 -1943). Porto Alegre: Oficinas Gráficas da Livraria do Globo, 1942.

WACHOWICZ, R. C. Obrageros, mensus e colonos: história do oeste paranaense. Curitiba: Vicentina, 1987.

Recebido em junho de 2017.

Aceito em agosto de 2017. 